\title{
Conjoined nerve root: case illustration
}

\author{
Andrew K. Chan, MD, Rory R. Mayer, MD, Praveen V. Mummaneni, MD, and \\ Dean Chou, MD
}

Department of Neurological Surgery, University of California, San Francisco, California

https://thejns.org/doi/abs/10.3171/2019.12.SPINE191226

KEYWORDS conjoined nerve root; developmental; anomaly; lumbar

$\mathrm{T}$ HIS 27-year-old man presented with a right-sided, congenital hemivertebra between L4 and L5 associated with spondylolisthesis, lumbar scoliosis, and severe left L4 radiculopathy resistant to conservative management. He was taken to the operating room to undergo a left L4-5 transforaminal lumbar interbody fusion (TLIF), and during surgery, a conjoined L4-5 nerve root was encountered (Fig. 1). This was recognized when trying to access Kambin's triangle. ${ }^{1}$ This anomaly was not evident on preoperative imaging (Supplemental Fig. 1) and precluded a safe TLIF. Because the TLIF graft could not be inserted, the patient instead underwent a wide left L4-5 laminectomy with total facetectomy for decompression of the left L4 nerve root, and an instrumented fusion was performed. Postoperatively, the patient noted significant improvement in his leg pain.

\section{References}

1. Kambin P, Sampson S. Posterolateral percutaneous suction-excision of herniated lumbar intervertebral discs. Report of interim results. Clin Orthop Relat Res. 1986;(207):37-43.

\section{Disclosures}

Dr. Chan reports that he has received non-studyrelated research support from Orthofix Medical, Inc.
Dr. Mummaneni reports that he is a consultant for the following: DePuy Synthes, Stryker, and Globus; he has received funding for non-study-related clincal or research efforts that he oversees from NREF and from AOSpine. He has received royalties from DePuy Synthes, Thieme Medical Publishers, and Springer. Dr. Chou reports being a consultant for Medtronic and Globus; he reports receiving a small royalty from Globus.

\section{Author Contributions}

Conception and design: Chan, Mayer, Chou. Acquisition of data: Chan, Mayer, Chou. Analysis and interpretation of data: Chou. Drafting the article: all authors. Critically revising the article: all authors. Reviewed submitted version of manuscript: all authors. Study supervision: Chou.

\section{Supplemental Information Online-Only Content}

Supplemental material is available with the online version of the article.

Supplemental Fig. 1. https://thejns.org/doi/suppl/ 10.3171/2019.12.SPINE191226. 


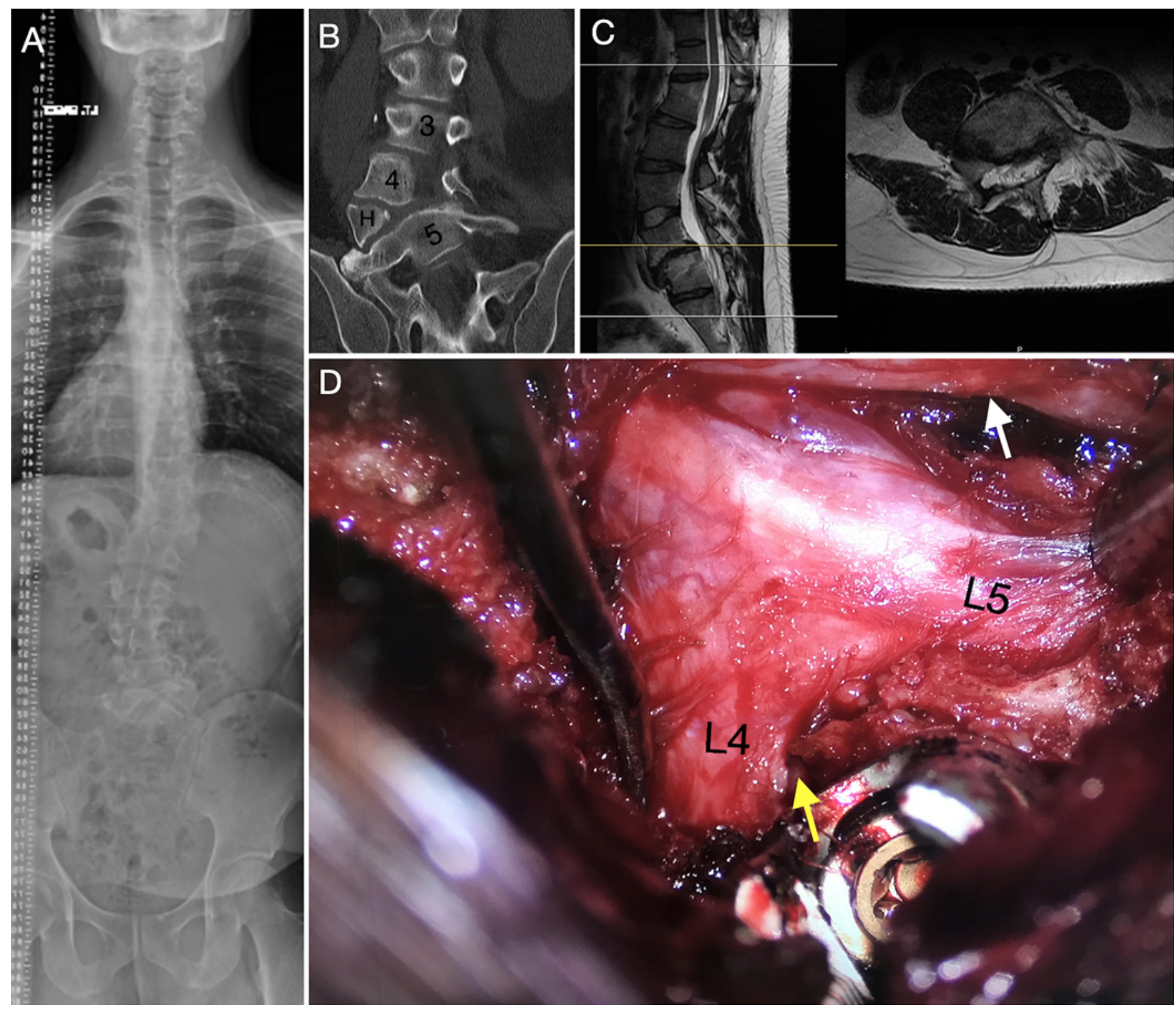

FIG. 1. A: Anteroposterior 36 -inch radiograph demonstrating lumbar scoliosis. B: Coronal CT scan showing the congenital hemivertebra (labeled $H$ ) between L4 (labeled 4) and L5 (labeled 5). C: Sagittal T2-weighted MR image demonstrating L4-5 spondylolisthesis (left). Axial T2-weighted MR image showing severe left L4 foraminal stenosis (right). The yellow scout line on the left panel shows the level of the corresponding axial image on the right panel. D: Intraoperative microscopic image demonstrating the conjoined L4-5 nerve root complex. The upper left corner of the image is cephalad and the bottom right corner of the image is caudal. The pedicle screw-inserted into the left L5 pedicle-is seen in the image. The yellow arrow and white arrow indicate the obscured L4-5 disc space and the thecal sac, respectively. Figure is available in color online only. 